\title{
Assessment of Colloidal Silver Impregnated Ceramic Bricks For Small-Scale Drinking Water Treatment Applications
}

\author{
Daniel M. Nover* \\ $\mathrm{PhD}$ Candidate, Department of Civil and Environmental \\ Engineering \\ University of California - Davis \\ Davis, CA, 95616 \\ dmnover@ucdavis.edu \\ Geetika Joshi \\ PhD Candidate, Department of Land, Air and Water \\ Resources \\ University of California - Davis \\ Davis, CA, 95616 \\ gjoshi@ucdavis.edu
}

\author{
Erica R. McKenzie* \\ PhD Candidate, Department of Civil and Environmental \\ Engineering \\ University of California - Davis \\ Davis, CA, 95616 \\ ermckenzie@ucdavis.edu \\ William E. Fleenor, PhD \\ Assistant Project Scientist, Department of Civil and \\ Environmental Engineering \\ University of California - Davis \\ Davis, CA, 95616 \\ wefleenor@ucdavis.edu \\ * Authors contributed equally
}

Abstract - Silver (Ag) has been used for its antiseptic qualities for thousands of years, including recent applications for point-of-use drinking water disinfection via colloidal silver-coated filtration devices. A novel deployment of colloidal silver was tested in which a ceramic substrate was coated with colloidal silver for suspension in a drinking water storage tank to provide continual, low-maintenance disinfection. Harvested rainwater contained appreciable total coliform concentrations $(>200 \mathrm{CFU} / 100 \mathrm{~mL}$ but $<1 \mathrm{CFU} E$. Coli/100 $\mathrm{mL}$ ). When the harvest rainwater was stored in a tank with the silver-coated substrate, disinfection was quick and efficacious $(t=30$ minutes resulted in $<1 \mathrm{~mL}$ coliforms $/ 100 \mathrm{~mL}$ ). An $E$. coli challenge solution was created by amended rainwater with canine feces. The treatment system with elevated silver concentrations $(\sim 300$ ppb silver $)$ had partial disinfection immediately and complete disinfection within 24 hours. The treatment system with lower silver concentrations ( 165 ppb silver) had more erratic initial disinfection, but complete disinfection was achieved within 96 hours. Silver concentrations $>100 \mathrm{ppb}$, which were routinely observed, warrant note as $100 \mathrm{ppb}$ is the US EPA secondary drinking water standard. Davis tap water was used in a flow-through setup to test substrate longevity. The treatment systems maintained a steady state silver concentration $(\sim 60 \mathrm{ppb})$ for at least 60 days of continual use. Water residence time did not have a significant impact. Results suggest that colloidal silver-coated substrates may be a feasible approach to small scale water treatment systems but ensuring safe drinking water requires careful attention to sizing substrates, cistern residence time, duration of treatment effectiveness, in addition to cultural appropriateness and community acceptance.

Index Terms- Coliform, colloidal silver, drinking water treatment, point of use, rainwater harvesting 


\section{Introduction and Objectives}

Renewed interest amid recent technological advances has spurred promotion of colloidal silver (Ag) nano-particles for use in water treatment with applications for both sophisticated systems ${ }^{1,2}$ as well as for small-scale decentralized systems in developing countries. One of the most high profile uses of colloidal silver in small scale drinking water treatment applications is for ceramic pots, candle style filters, and paper filters coated with silver solutions. All of these treatment methods have been shown to be effective in removing water-borne pathogens. ${ }^{3,4,5,6}$

Because of the relatively large pore size of these filters, small pathogens such as viruses and smaller bacterial cells can pass through the filters untreated. These filters are often impregnated with colloidal silver with the intention of destroying these smaller pathogens. There is some degree of doubt in the literature as to the benefit derived from the addition of silver to these pots, partly because the silver compounds that are applied tend to leach out quickly (80\% reduction in six weeks) after filter construction ${ }^{4}$ and in at least one study, pots impregnated with silver were shown to remove viruses less efficiently that pots without silver ${ }^{7}$. Overall, however, colloidal silver is viewed as an important additive capable of eliminating pathogens below the size that filters can remove on their $\mathrm{own}^{8}$ and its ability to eliminate viruses is the subject of current research.

Although colloidal silver is routinely added to the filter types described above and several colloidal silver products have been designed and marketed for direct application to drinking water treatment in small systems (SilverDYNE, Nano Silver, etc.), there is very little literature focused the efficacy of silver in treatment or on the impact of silver on human or environmental health. Some research has explored the potential for silver treatment of municipal scale drinking and wastewater systems to prevent biofilm development in distribution networks ${ }^{9,10}$ and to destroy viruses and bacteria ${ }^{12,13}$. There is a great deal of research focused on colloidal silver destruction of various pathogens (viruses, bacteria, and protozoans) in experimental investigations. There is overwhelming evidence supporting the destruction of important bacterial indicator organisms such as E. coli and E. faecalis by colloidal silver both in laboratory conditions $^{14,15}$ and in field tested clay pot filters ${ }^{16}$, although in the latter case, it is difficult to separate the effect of the filter itself from the effect of the colloidal silver coating ${ }^{8}$. These studies suggest that there is potential for colloidal silver as a point-of-use drinking water treatment method in small scale systems. In the developing world context, effective virus removal has not been demonstrated for silver impregnated clay pot filters and no field studies were identified in which colloidal silver was directly applied to drinking water and systematically tested for pathogen removal.

A novel deployment of SilverDYNE® (a colloidal silver suspension) was tested in this study, entailing application of the solution to ceramic substrates intended for placement in cisterns for small-scale water treatment. The objectives of this research are to: 1) investigate the safety of harvested, untreated, stored rainwater; 2) test silver-coated substrates for its ability to destroy coliforms; 3) determine if water exposed to colloidal silver-coated substrates produces solution-phase silver concentrations that exceed health guidelines; 4) estimate the lifetime of these silver impregnated ceramic substrates; and 5) compare measurements of fecal indicator bacteria using an EPA approved method and a non-EPA approved method used with and without laboratory quality incubation. It should be noted that, while this work is motivated by the continuing activities of Engineers Without Borders at UC Davis in developing appropriate technologies for drinking water treatment in developing countries, this is a screening level study 
of a novel treatment technology. In addition to the technical, methodological, and financial barriers to using such a treatment method, a whole host of issues related to community acceptance, cultural appropriateness, and community involvement would need to be evaluated on a context-specific basis before implementation could be considered, as is the case with any novel technology.

\section{Methods}

\section{Experimental Setup}

A 3,000 L ferrocement tank, located in Davis, CA, was used to collect rainwater runoff from an adjacent roof. The ferrocement tank was constructed in the summer of 2008, and had been collecting rainwater since, with minimal use. The harvested rainwater was used to fill four 220liter plastic drums. Stoneware ceramic substrates $\left(\sim 6.04 \mathrm{~m}^{2}\right.$ of total silver-coated substrate) were produced and coated with colloidal silver by the World Health Alliance International. The ceramic substrates were extrusion produced (Brad Ponack Ceramics), dipped in a 3.5\% (by volume) solution of SilverDYNE® colloidal silver (a commercially available product designed for small-scale drinking water treatment), baked at $180^{\circ} \mathrm{C}$ for $1 \mathrm{hr}$, rinsed, air-dried, and then baked at $100^{\circ} \mathrm{C}$ for $48 \mathrm{hrs}$. The baked and washed substrates were suspended in two of the tanks and two of the tanks were left untreated (Figure 1). We created two hypothetical uses of the tanks; one in which the tank is used by a family of six for drinking water only $(2 \mathrm{~L} /$ person/day or $12 \mathrm{~L}$ withdrawn daily and replaced with water from the large rainwater tank - hereafter referred to as ' 12 L exchange') and another that would be used for the entire family's water demand (20 $\mathrm{L} /$ person/day or $120 \mathrm{~L}$ withdrawn daily - hereafter referred to as '120 L exchange'; see Table 1).

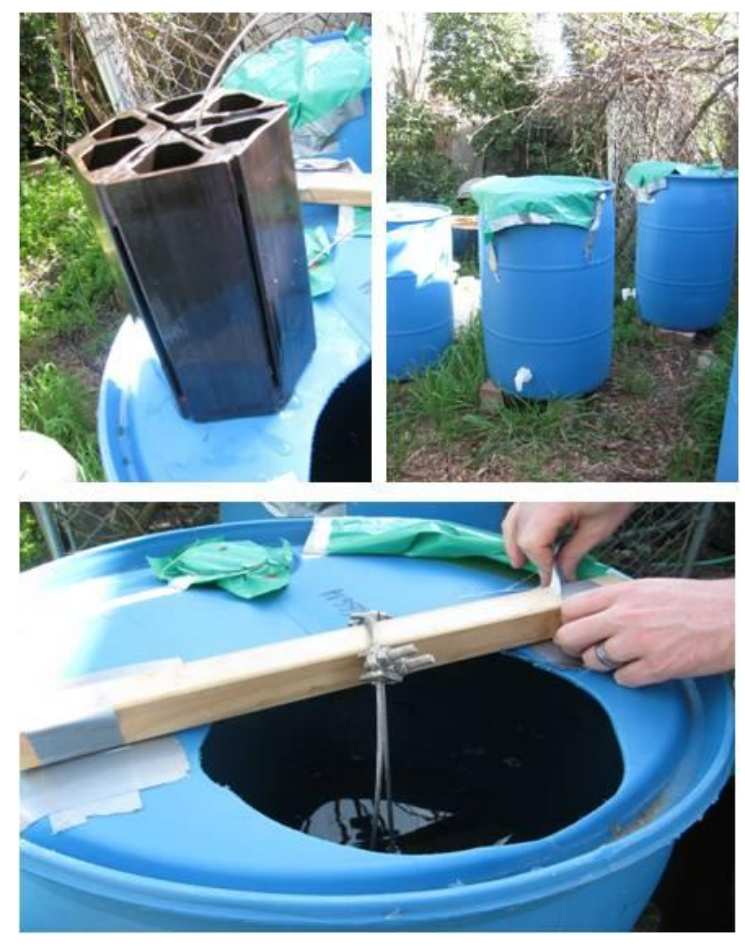

FIGURE 1

COLLOIDAL SILVEER-COATED SUBSTRATE (TOP LEFT), FOUR 220 L TANKS USED IN THIS STUDY (TOP RIGHT) AND SUSPENDING THE BRICK IN TANKS FOR TREATMENT (BOTTOM). 
TABLE 1

SUMMARY OF EXPERIMENTAL TREATMENTS

\begin{tabular}{rcccc} 
Tank \# & Treatment & Scenario & $\begin{array}{c}\text { Exchange } \\
\text { volume }(\mathrm{L})\end{array}$ & $\begin{array}{c}\text { Mean residence time if daily } \\
\text { exchanges employed (d) }\end{array}$ \\
\hline 1 & Control - no silver & Drinking water & 12 & 16.7 \\
2 & Control - no silver & All water & 120 & 1.67 \\
3 & Silver & Drinking water & 12 & 16.7 \\
4 & Silver & All water & 120 & 1.67 \\
\hline
\end{tabular}

\section{Experimental Phases}

The colloidal silver-coated substrates were tested in three phases: 1) to test the treatment approach in the presence of relatively clean harvested rainwater; 2) harvested rainwater spiked with a canine feces slurry to test the treatment approach with heavily contaminated source water; and 3) Davis municipal tap water for extended testing to estimate the lifespan of the silver-coated substrate. Experimental phases one and two were conducted in semi-batch mode, where the specified exchange volume (12 L or $120 \mathrm{~L}$ per exchange) was removed and subsequently replaced with harvested rainwater. The exchange schedule is shown in figure 2 . There was a seven day break between experimental phases one and two. Experimental phase three was conducted in a continuous flow-through setup with municipal tap water, where the flow rates were set such that 12 or 120 liters were exchanged daily. This experiment was run for 76 days and samples were collected approximately weekly for silver analysis; at day 52 and day 76, effluent samples were filtered using a $20 \mathrm{~nm}$ filter, where the filtrate was defined as the dissolved fraction. Due to the presence of chlorine in the influent water, bacterial analysis could not be pursued. Nalgene sample bottles $(500 \mathrm{~mL})$ were used to collect effluent samples from a spigot mounted $15 \mathrm{~cm}$ above the bottom of the tank and the samples were transported to the cold storage room in the Department of Civil and Environmental Engineering at UC Davis. 


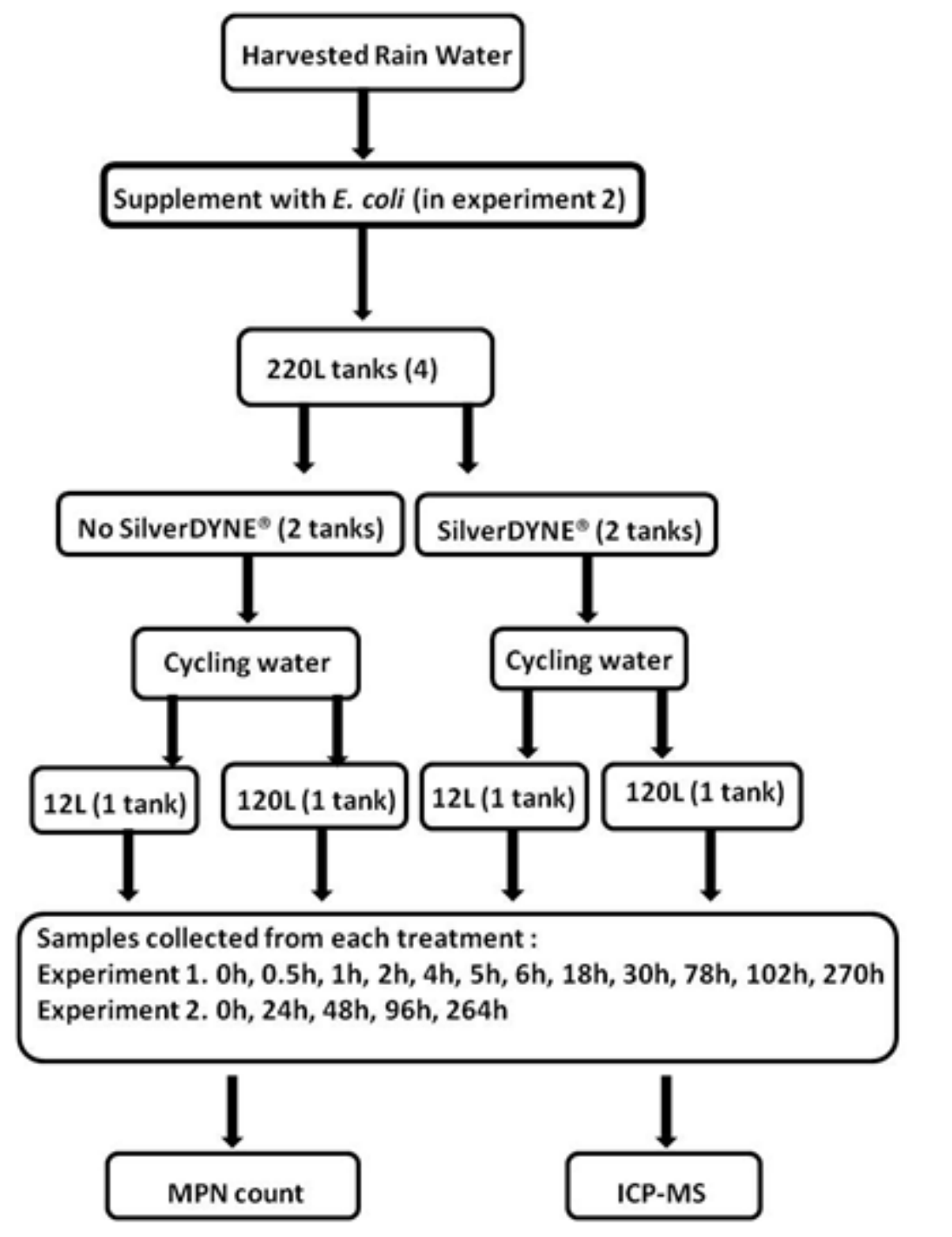

FIGURE 2

SCHEMATIC SHOWING SAMPLING METHODOLOGY FOR ALL TREATMENTS

\section{Coliform Testing Methods}

IDEXX Colilert ${ }^{17}$ was used in this study to detect coliforms and the fecal indicator organism E.coli. Only undiluted samples were tested, as drinking water safety was the primary goal of the study. Coliform and E. coli were tested per manufacturer instructions. An undiluted sample $(100 \mathrm{~mL})$ was combined with the manufacturer provided aliquots of nutrients and sodium thiosulfate, sealed into an IDEXX 101 well Quantitray, and incubated at $35+/-0.5^{\circ} \mathrm{C}$ for 24 hours. Sodium thiosulfate has been previously demonstrated to effectively quench silver's bactericidal properties for the silver concentrations observed in this study. Samples were incubated and counted in the presence and absence of ultra violet light to determine the number of total coliforms (yellow cells) and E. coli (fluorescent cells) using Most Probable Numbers (MPN) provided by IDEXX. Samples were tested in triplicate for experiment one and in duplicate for experiment two. 
Additionally, $1 \mathrm{~mL}$ of select sample was plated on $3 \mathrm{M}^{\mathrm{TM}}$ Petrifilm ${ }^{\mathrm{TM}}$ E.coli/Coliform count plates in triplicate. Many areas of the developing world lack consistent electricity which can complicate microbial testing. To overcome this, the authors explored the use of "human incubators," whereby a volunteer affixes Petrifilm ${ }^{\text {TM }}$ onto their person for 24 hours, using body heat for incubation purposes. ${ }^{18,19}$

\section{Metals Testing Methods}

Duplicate or triplicate samples were collected for metals analysis. Collected samples were acidified (1\% nitric acid, trace metals grade; Fisher) and stored at $4^{\circ} \mathrm{C}$. Analysis was completed with an Inductively Coupled Plasma Mass Spectrometer (ICP-MS; Agilent 7500i; EPA method 6020) which was calibrated with a multi-element standard with concentrations ranging 0.01-100 ppb (Centrispex Spex2A), and was verified with the standard reference material 1643e (NIST). Silver limit of detection (LOD; seven blanks, $\mu+3 \cdot \sigma$ ) was $2.3 \mathrm{ppb}$, which was less that the concentrations observed for all substrate-exposed effluent samples. Some of the analyzed samples had silver concentrations that exceeded the highest analyzed standard concentration ( five-fold), however separate analyses have demonstrated the ICP-MS silver response to be linear though $10,000 \mu \mathrm{g} / \mathrm{L}$. The derived values should be viewed as estimates.

\section{Results and Discussion}

\section{Untreated, stored rainwater}

Harvested rainwater stored in the ferrocement tank had substantial total coliform concentrations but did not have detectable E. coli concentrations (Figure 3). Untreated water from the tank prior to experimental set-up had total coliforms $>200 \mathrm{CFU} / 100 \mathrm{~mL}$ (exceeding the resolution available via the normal resolution IDEXX Colilert given undiluted samples). IDEXX Colilert test is specific for coliforms, with the capability to suppress up to $2 \times 10^{6}$ heterotrophs and to detect single $E$. coli CFU per $100 \mathrm{ml}$ of the water sample (IDEXX Laboratories). The tanks that did not receive silver-coated substrate treatment did not show significant changes (i.e., remained $>200$ $\mathrm{CFU} / 100 \mathrm{~mL}$ ) in total coliform numbers except for the last three collected samples, wherein the total coliform counts were reduced to low concentrations $(\mathrm{t}=78,102$ and $270 \mathrm{~h} ; 0.5-5.85$ CFU/100 mL).

The fact that coliforms in harvested rainwater declined in concentration without treatment is noteworthy. There are several factors that may have led to this outcome. First, relatively clear water was generally taken from the top of the large rainwater harvester and moved to the smaller experimental tanks. Consequently, particle-bound nutrients were likely not moved into the treatment tanks, leaving coliforms with an inadequate food source. Second, settling within the experimental treatments likely led to the loss of both coliforms and particles/nutrients from the water column. Although studies have shown rainwater to be quite variable in terms of water quality and microbiological contamination, sometimes containing both disease causing bacteria and protozoa ${ }^{20}$, the observations in this study are an encouraging case study suggesting ways to produce high quality harvested rainwater. Even in the absence of treatment, these results suggest that rainwater harvesters which effectively limit both sunlight and material from catchment surfaces (including leaf litter, animal feces, etc.) through effective first flush mechanisms can generate increasingly clean water with greater storage time. Previous research has also indicated that the microbial water quality consideration was mostly affected by cleanliness level of the contributing area ${ }^{21}$. 
Contamination in the form of canine feces was added because the harvested rainwater contained non-detectable concentrations of $E$. coli. We chose to source $E$. coli from canine feces to mimic situations likely to arise in actual operation of rainwater harvesting systems, where the canine feces were provided as a one-time pulse at the beginning of phase two; water exchanges were conducted using the harvested rainwater, which was known to contain coliforms but no $E$. coli. The total and E. coli coliform results of the second experiment are shown in Figure 4. The drinking water scenario control tank had total coliform and E. coli concentrations that exceeded enumeration ( $>200 \mathrm{CFU} / 100 \mathrm{~mL}$ ) throughout the second experiment. Water was withdrawn and replaced four times during the second experiment, resulting in 0.22 and 2.2 tank volumes being cycled for the $12 \mathrm{~L}$ and $120 \mathrm{~L}$ exchange scenarios, respectively. In the short residence time control tank (120 L exchange scenario), total coliform counts remained high until the $264 \mathrm{~h}$ time point at which there was $>50 \%$ and $>90 \%$ reduction in total coliforms and $E$. coli, respectively (1.75 tank volumes cycled). At least part of the observed reduction is due to the water cycling with clean (not amended with feces) harvested rainwater, as 55\% of tank volume cycled each time for the all water needs scenario. Assuming complete mixing (i.e., homogeneous), coliform concentration reduction due to water exchanges would be proportional to the fractional volume exchanged (i.e. $\mathrm{C}_{1}=\mathrm{C}_{0} *(1-\mathrm{f})$, where $\mathrm{C}_{0}$ and $\mathrm{C}_{1}$ are the pre-cycling and post-cycling concentrations, respectively, and $\mathrm{f}$ is the fractional volume exchanged $=$ volume exchanged/tank volume). The reduction seen in $E$ coli. exceeds that simply explained by water exchanges, which demonstrates that some bacterial inactivation was occurring in the control tanks. 


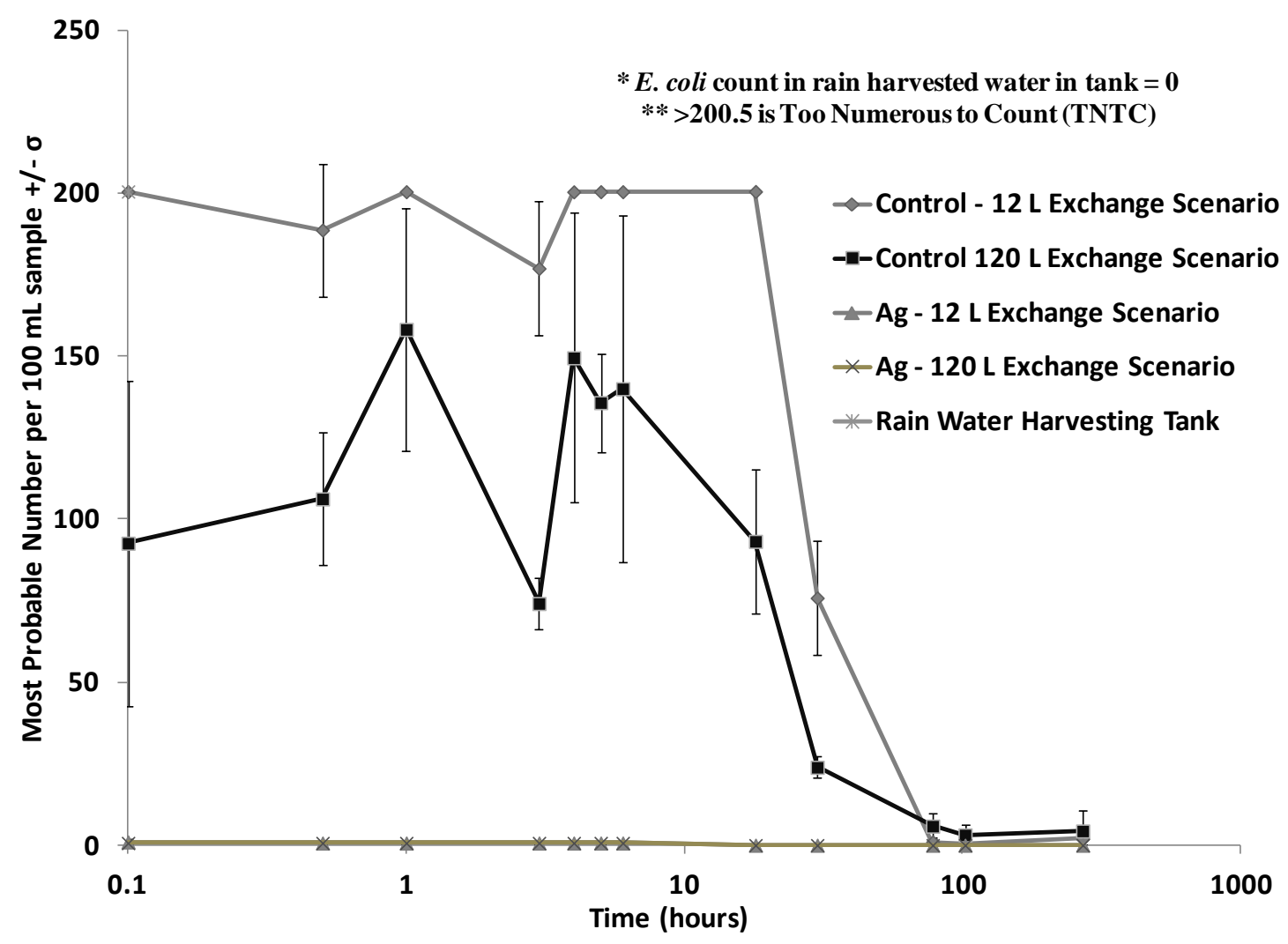

FIGURE 3

TOTAL COLIFORM COUNTS PER 100ML IN WATER SAMPLES FROM THE FOUR EXPERIMENTAL TANKS DURING EXPERIMENT 1 OF THE STUDY. ERROR BARS SHOW ONE STANDARD DEVIATION BASED ON TRIPLICATE MEASUREMENTS. NO ERROR BARS INDICATE INCALCULABLE STANDARD DEVIATION BECAUSE ALL MEASUREMENTS WERE EITHER ZERO OR TOO NUMEROUS TO COUNT.

\section{Stored rainwater treated with silver-coated substrates}

In the presence of the silver-coated substrates, high initial concentration of coliforms were reduced to non-detectable levels, even before the first sample (collected at time 0 though there was some exposure during the barrel filling process, Figure 3). This indicated that treatment using the new substrate was quick and effective in the presence of suspended or dissolved silver concentrations of 98 and $\sim 200 \mathrm{ppb}$ for the two treatment tanks. Total coliform and E. coli concentrations remained non-detectable for the remainder of the first experiment (shown in Figure 3 ), with the exception of one outlying measurement ( $2 \mathrm{hr}$ ).

For both treatment conditions, samples collected at $\mathrm{t}=24 \mathrm{hrs}$ were completely inactivated; however, the $120 \mathrm{~L}$ exchange scenario treatment tank contained $>200 \mathrm{CFU} / 100 \mathrm{~mL}$ (total coliforms and $E$. coli) at $\mathrm{t}=48 \mathrm{hrs}$, and returned to $<1 \mathrm{CFU} / 100 \mathrm{~mL}$ at $\mathrm{t}=96 \mathrm{hrs}$. In no other treated water sample were high counts of coliforms (or E. coli) seen after 24 hours. We therefore suspect that mishandling of samples during laboratory analysis led to this single erroneous data point. However, based on the available data and trends, we are unable to say which sample (24 hour or 48 hour) from the all needs treatment scenario tank $(120 \mathrm{~L}$ exchange scenario) was mishandled and therefore erroneous. Regardless, by 96 hours, all treated water had too few coliforms (and E. coli) to count. These results are summarized in Figure 4. 

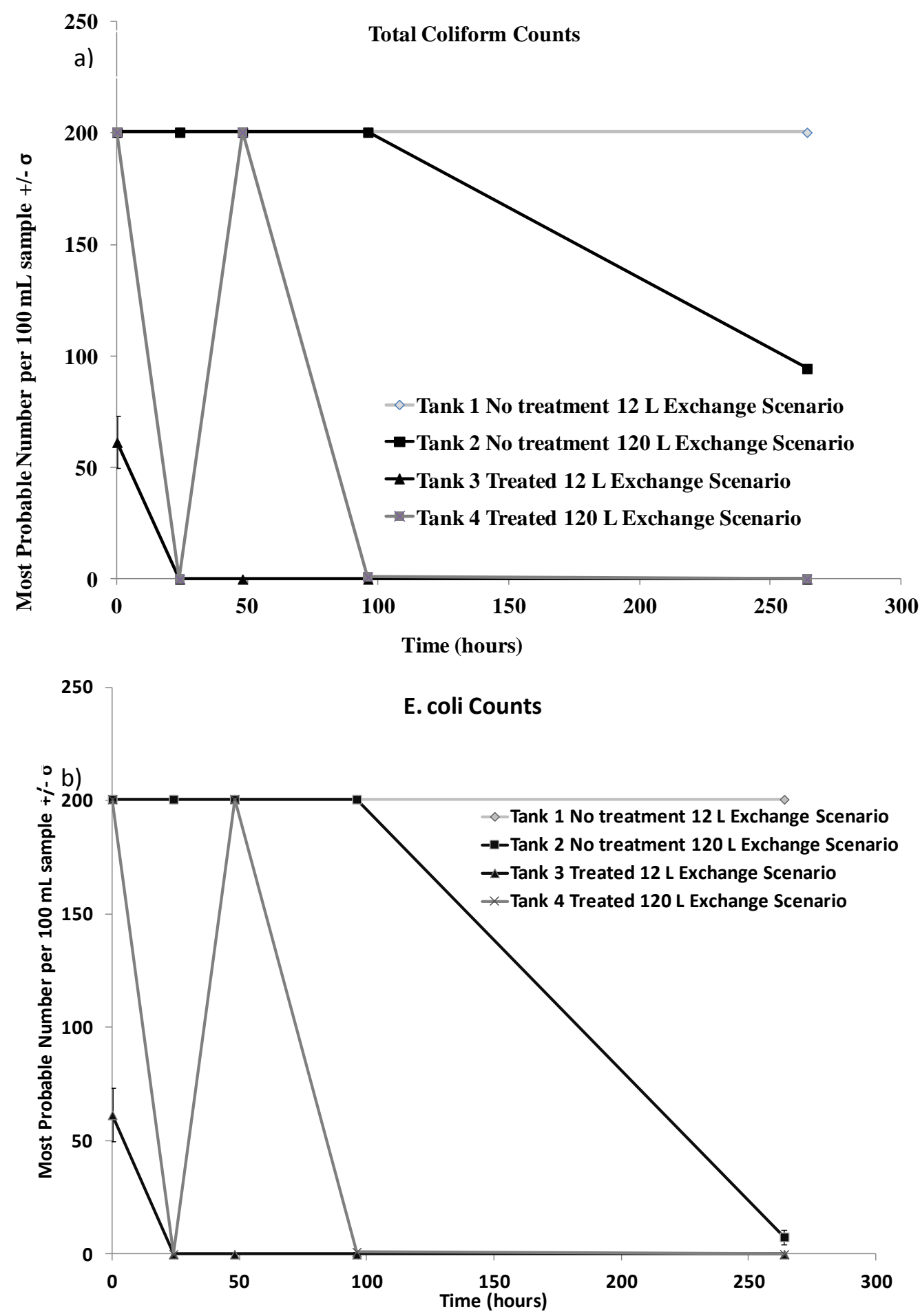

FIGURE 4

TOTAL COLIFORM (A) AND E. COLI (B) MPN COUNTS PER 100 ML SAMPLE AFTER SUPPLEMENTING TANKS WITH E. COLI. NO ERROR BARS INDICATE INCALCULABLE STANDARD DEVIATION BECAUSE ALL MEASUREMENTS WERE EITHER ZERO OR TOO NUMEROUS TO COUNT. 


\section{Solution phase silver concentrations}

Bulk solution silver concentrations, which likely included colloidal and dissolved silver, from both phases 1 and 2 are shown in Figure 5. Conventional SilverDYNE®, which is sold as a suspension, was analyzed at the recommended dose for high turbidity waters ( 2 drops into $2 \mathrm{~L}$ ), which resulted in a total silver concentration of $147 \mathrm{ppb}$. Silver concentration in the harvested rainwater was essentially $0 \mathrm{ppb}$, and silver concentration in the control tanks averaged $<1 \mathrm{ppb}$ (i.e. below the LOD; maximum control tank concentration $5.7 \mathrm{ppb}$ ). Samples were taken for silver concurrently with coliform sampling, as previously described. The initial concentrations (time 0) in the experimental tanks were $98 \mathrm{ppb}$ and $200 \mathrm{ppb}$. The two treatment tanks continued to have divergent silver concentrations during the entire period prior to the first water exchange, with final pre-water exchange $(\mathrm{t}=30 \mathrm{~h})$ experimental tank concentrations of $\sim 160 \mathrm{ppb}$ and $\sim 40 \mathrm{ppb}$. The observed in-barrel silver concentration differences among the samples collected prior to water cycling could be due to differences in filling technique or substrate manufacturing. Filling differences, such as pouring directly onto the brick, could result in increased wash-off of colloidal silver material, which could account for the difference in the initial concentrations $(t=0)$. Inconsistencies in the manufacturing process could result in the differences in the subsequent product wash-off/dissolution $(\mathrm{t}<30 \mathrm{hrs})$.

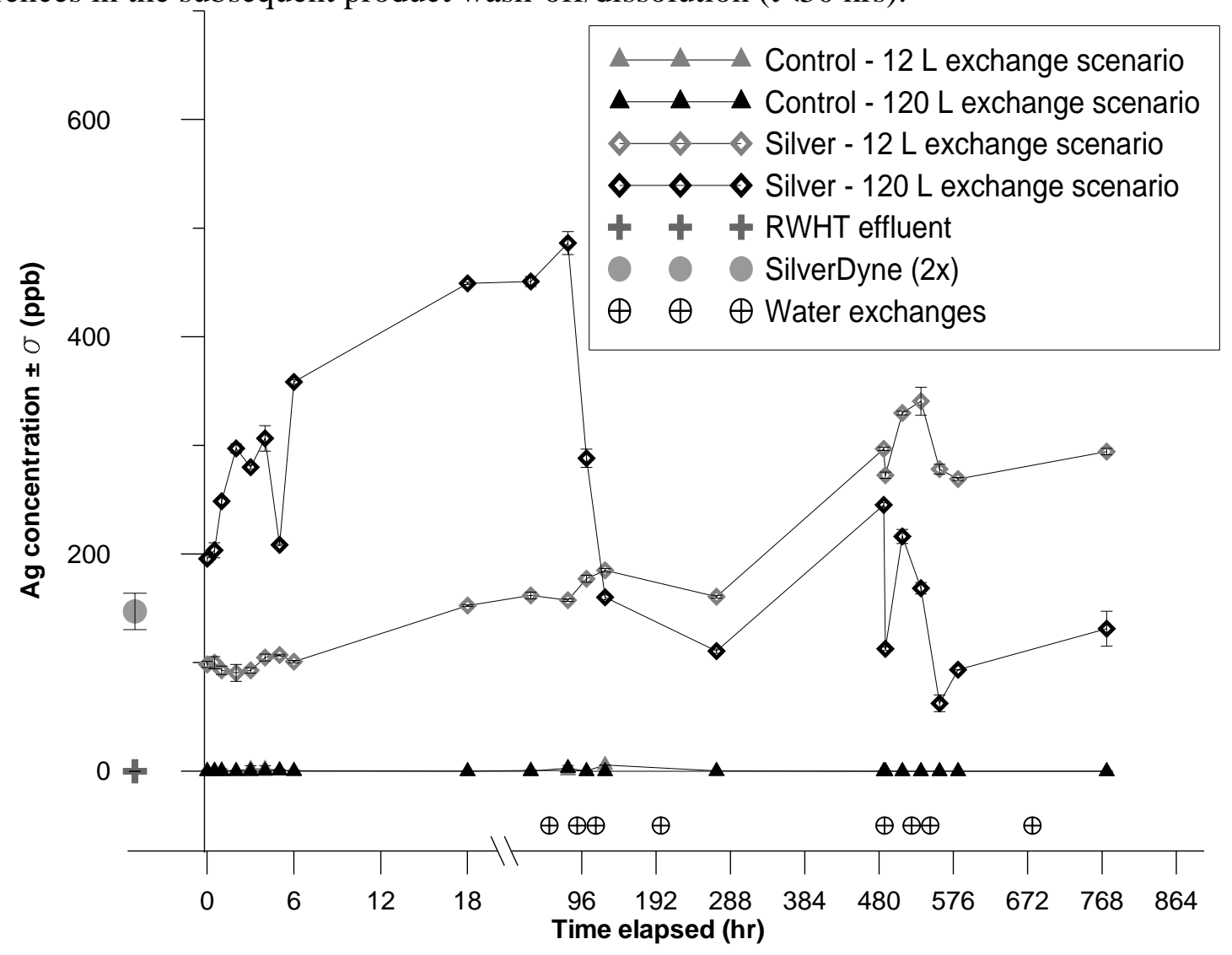

FIGURE 5

SILVER CONCENTRATION IN TANK EFFLUENT. AVERAGES AND STANDARD DEVIATIONS FOR FOR $\mathrm{T}<300$ HRS WERE CALCULATED FROM TRIPLICATES, WHILE DATA FOR T $>300$ HRS WERE CALCULATED FROM DUPLICATES. 
Following the eleventh sampling, water exchanges were initiated (indicated by the crossed circles in Figure 5) at the two prescribed exchange volumes. In the treated $12 \mathrm{~L}$ exchange scenario, the effect of water exchanges was minimal; in several instances, more silver was released in the storage time between sampling events than was removed in the $12 \mathrm{~L}$ cycling volume, leading to increasing silver concentration (e.g. first cycling event). In the $120 \mathrm{~L}$ exchange scenario, a rapid reduction in-barrel silver concentration was observed, and the silver concentration was reduced from $\sim 490 \mathrm{ppb}$ to $110 \mathrm{ppb}$ in $\sim 1.7$ tank volumes.

In an attempt to understand the longer term behavior of the silver release from the substrates, the water cycling was modeled assuming a well-mixed system (i.e., homogeneous silver concentration). The silver concentration that is carried over from the previous cycle was calculated (assuming uniform silver concentration within the tank; referred to as residual), and the silver release (via dissolution or suspension) was determined by difference. The results of these calculations are shown in Figure 6. The differences in resultant initial tank concentrations, shown as the first column in the graph, once again demonstrate that the two substrates did not initially release silver at the same rate.

Looking beyond the first column, one can examine the impact of the residual and the release of silver as it changed based on cycling volume and over time. In almost all cases, the residual (concentration remaining from previous releases) is the dominant portion for both scenarios. The exception to this is the column labeled "interim", which was the inactive period (following daily cycling for three days) between the two experiments during which the tanks were left undisturbed for seven days. The silver concentration at the end of the interim period had approximately equal contributions from residual and newly released silver. When contrasting the two scenarios, we noticed that negative release contributions were commonly calculated for tank 4 (120 L exchange scenario), and occasionally for tank 3 (12 L exchange scenario). Though it is physically possible for the silver to (re-)adhere to the substrates or plastic tank walls, the authors feel that this is unlikely. It is also unlikely that it is analytical error, as replicate analysis were generally consistent (relative standard deviation of $<5 \%$ if almost all cases). It is more likely that the initial uniform (homogeneous) silver assumption was inaccurate. If the silver is being released from bricks as particulate silver (or agglomerates), the silver particles would settle to the bottom of the tank and be preferentially removed as the tank is drained from a port near the bottom of the barrel. The settling of the particulate/agglomerated silver would result in a non-uniform silver distribution, where the bottom layer would contain more silver than the upper water layers. Since the effluent concentration would not be representative of the entire tank, the amount of total suspended/dissolved silver in the tank would be overestimated (the residual), which would result in an underestimation of the amount of silver removed during cycling. This evidence indicates that at least some of the silver is being released in a particulate form or is adsorbing to particles within the tank, and therefore settling. 


\section{A) 12 L exchange scenario}

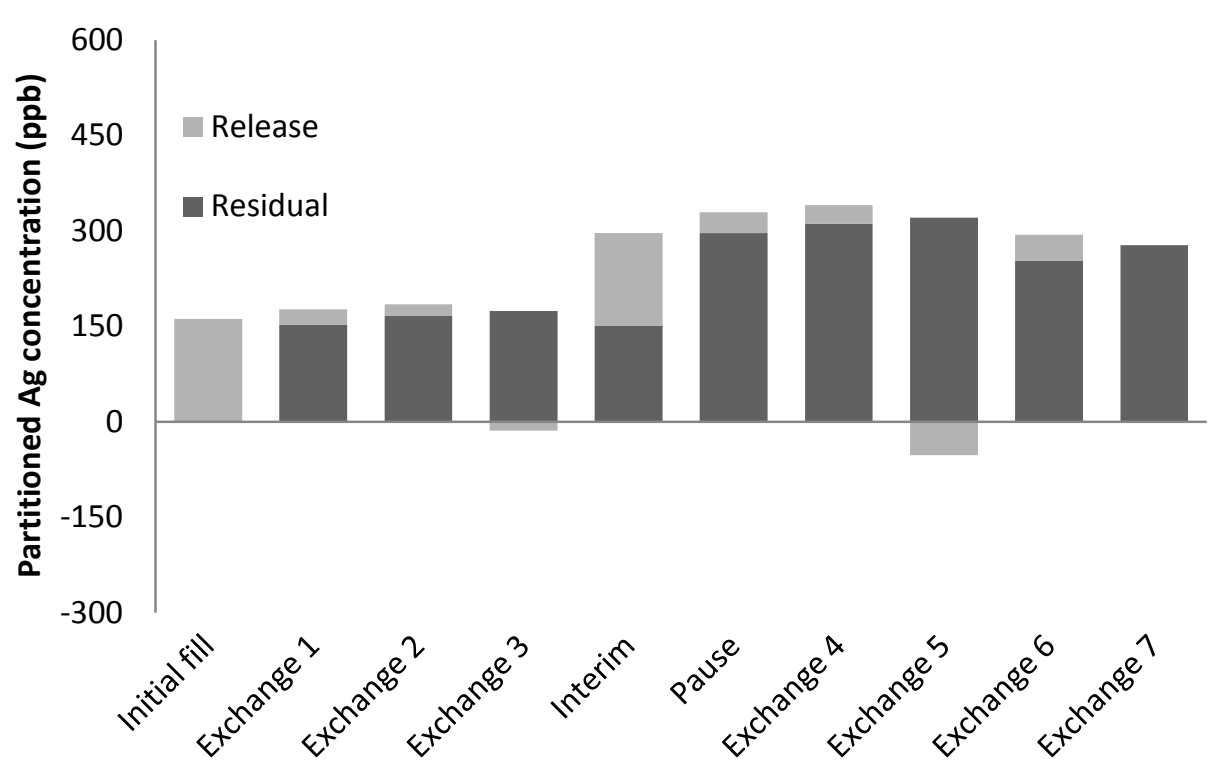

\section{B) 120 L exchange scenario}

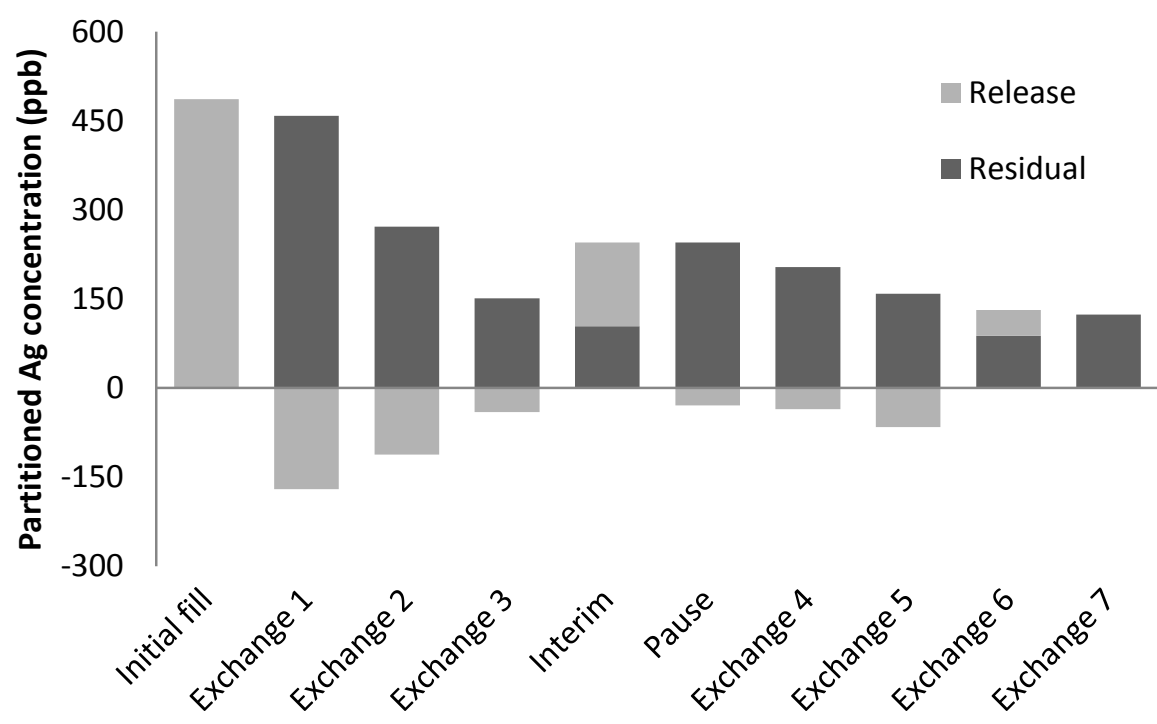

FIGURE 6

PARTITIONING OF SILVER CONCENTRATION INTO PREVIOUSLY RELEASED (RESIDUAL) AND RECENTLY RELEASED (RELEASE) SILVER FOR TANK 3 (A) AND TANK 4 (B)

The early silver concentrations observed in this study indicate a possible human health concern since many of the values in experimental phases one and two exceeded the $100 \mathrm{ppb}$ guideline. Tank sizing is an important component that needs to be carefully matched with silver-coated 
substrate surface area, where coated surface area is expected to be correlated with silver release, via colloidal washoff and/or dissolution. The substrate surface area needs to be sufficiently large to release adequate silver to achieve disinfection. However, too large of a surface area will result in excessive silver washoff/dissolution, which could result in solution phase silver concentrations that exceed health guidelines. Success of this deployment method will depend on correct pairing of substrate surface area and tank sizing.

\section{Estimation of coated substrate lifespan}

Figure 7 shows results from the flow through experiment designed to demonstrate the silver concentration in experimental tanks over time. Interestingly, after an initial period (approximately the first 20 days) of increasing silver concentrations, concentrations remained relatively constant at just under $60 \mathrm{ppb}$ for the majority of the experimental period (about 60 days) regardless of residence time, indicating that both systems had reached a steady state. Despite treating substantially more water in the $120 \mathrm{~L}$ exchange scenario, silver concentrations remained approximately the same as the concentration in the $12 \mathrm{~L}$ exchange scenario tank. Not until day 67 is any substantial difference seen in silver concentration between 12 and $120 \mathrm{~L}$ exchange scenario treatments, and the $120 \mathrm{~L}$ exchange scenario concentration decreased while the $12 \mathrm{~L}$ exchange scenario tank remained relatively constant.

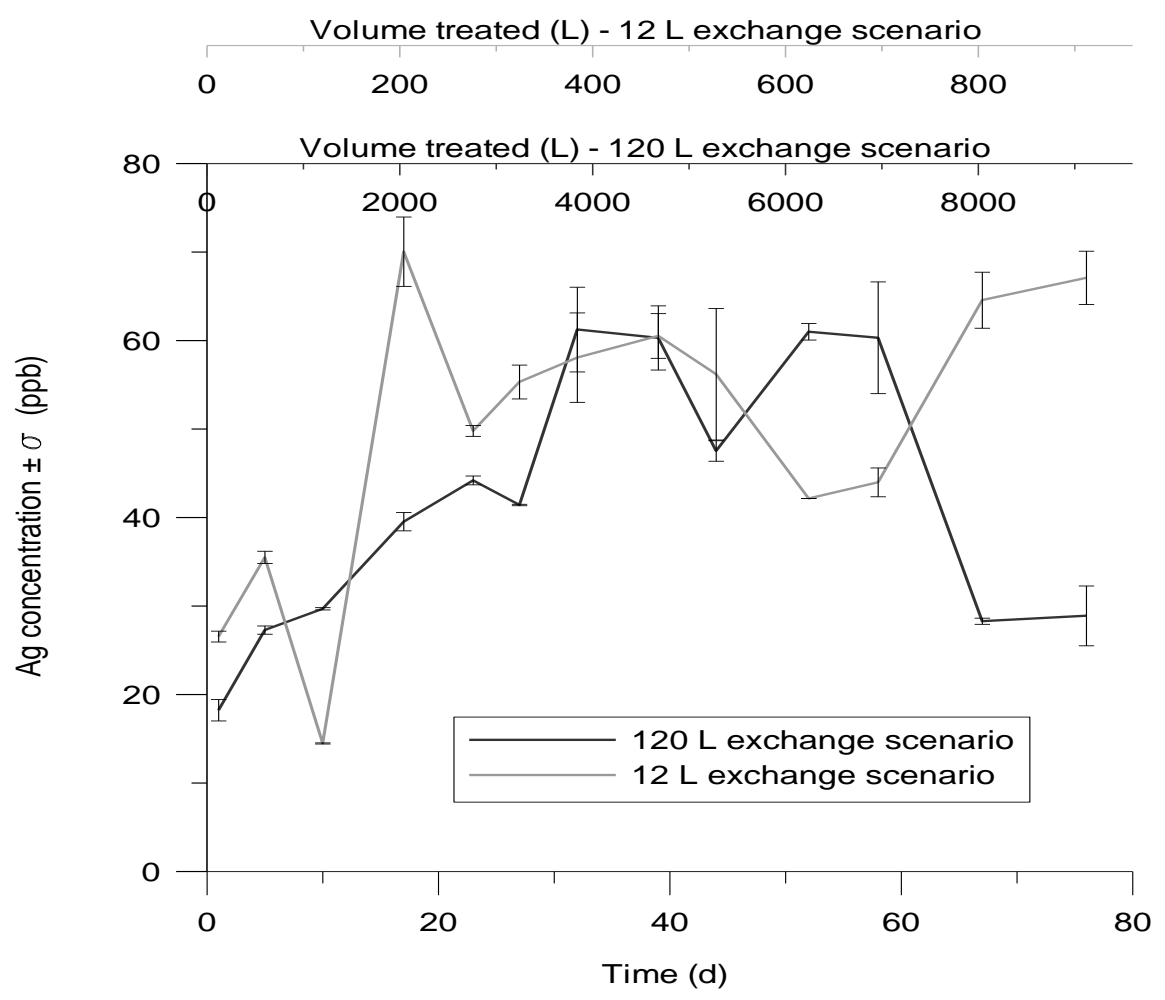

FIGURE 7

CONCENTRATION OF SILVER IN EXPERIMENTAL TREATMENTS DURING THE COURSE OF THE FLOW THROUGH EXPERIMENTS. BLACK AND GREY LINES SHOW SILVER CONCENTRATIONS IN THE SHORT AND LONG RESIDENCE TIME TREATMENT, RESPECTIVELY. BLACK DIAMONDS SHOW TIMING OF E. COLI ADDITION. 
Dissolved silver, operationally defined as $20 \mathrm{~nm}$ filtrate, included $58-76 \%$ of the total Ag, based on the evaluation conducted at day 52 and 76. Dissolved ionic silver (i.e. $\mathrm{Ag}^{+}$) is expected to be more efficacious than colloidal silver, however the filtrate was not verified to be ionic, but instead could include nano-silver particles (e.g. diameter of $10 \mathrm{~nm}$ ) or organic matter associated silver.

\section{Comparison of coliform enumeration methods}

Each sample collected during the first 6 hours of experiment 1 was plated in two triplicates on $3 \mathrm{M}^{\mathrm{TM}}$ Petrifilm ${ }^{\mathrm{TM}}$ E.coli/Coliform count plates with one such triplicate incubated via a "human incubator" and one in a controlled incubation chamber. However, there was a great deal of variation among the MPN/100 mL obtained from these plates for total coliforms, likely due to the small sample size $(1 \mathrm{~mL})$ applied to each plate. Therefore, we decided to use these data to indicate only presence or absence of coliform bacteria in the samples (Table 2).

In the treated tanks, no coliforms were detected by the Petrifilms ${ }^{\mathrm{TM}}$ at any of the sampling time points via either human or normal incubation. This is in contrast to positive detection on IDEXX Quanti-trays ${ }^{\circledR}$ seen in Experiment 1; however, the average MPN for the IDEXX was $<1$ per $100 \mathrm{~mL}$ of sample. Therefore, it is likely that when $1 \mathrm{~mL}$ sample was plated on the Petrifilms $^{\mathrm{TM}}$, none were detected. In five samples out of total 32, there were inconsistencies (presence of total coliforms via one method and absence via another method) in detection between human and laboratory incubated Petrifilm ${ }^{\mathrm{TM}}$ plates. Of these, four (highlighted in grey in Table 2) indicated absence when incubated at human body temperature while the other two methods indicated presence of coliforms in samples. This could be attributed to decreased temperature on the body exterior and the fact that stacked Petrifilms ${ }^{\mathrm{TM}}$ incubated on volunteers' bodies are not uniformly exposed to body heat, allowing for non-ideal conditions for colony formation. In cases of measurement discrepancies, both plates incubated in the laboratory and IDEXX Quanti-trays ${ }^{\circledR}$ indicated presence of coliforms, among which the lowest IDEXX recorded total coliform concentration was $74.17 \mathrm{CFU} / 100 \mathrm{~mL}$. One sample (Tank 2, 3 hours) showed the opposite trend - laboratory incubated Petrifilm ${ }^{\mathrm{TM}}$ plate showed absence of coliforms in sample detected positively by the other two methods. Although the number of samples tested is too small to provide robust statistical estimates of $3 \mathrm{M}^{\mathrm{TM}}$ Petrifilm ${ }^{\mathrm{TM}}$ E.coli/Coliform count plates, they have the potential to serve as a qualitative detection method when incubated under controlled conditions.

The use of $3 \mathrm{M}^{\mathrm{TM}}$ Petrifilm ${ }^{\mathrm{TM}}$ E.coli/Coliform count plates for field measurements of coliforms and $E$. coli as well as the efficacy of ambient temperature incubation has been examined in a previous study ${ }^{18}$. Although the previous study found good agreement between incubated and non-incubated samples and between samples measured using the field test in comparison to standard laboratory methods, our experience suggests that $3 \mathrm{M}^{\mathrm{TM}}$ Petrifilm ${ }^{\mathrm{TM}}$ count plates should be used with caution in the field, since 1) although the method is more or less good for presence/absence at high coliform concentrations, the method is inconsistent at lower coliform concentrations and 2) user error can generate inconsistencies in incubation temperature depending on number of plates stacked, closeness to the body, etc. 
TABLE 2

A COMPARISON OF THREE COLIFORMS DETECTION METHODS. PRESENCE/ABSENCE IS INDICATED BY +/-. ORDER OF METHODS IS: (I) $3 \mathrm{M}^{\mathrm{TM}}$ PETRIFILM $^{\mathrm{TM}}$ INCUBATED ON HUMAN VOLUNTEERS (H I $_{\mathrm{P}}$, (II)

$3 \mathrm{M}^{\mathrm{TM}}$ PETRIFILM $^{\mathrm{TM}}$ INCUBATED AT CONTROLLED TEMPERATURE ON A HUMAN BODY, UNDER LABORATORY CONDITIONS AND USING IDEXXQUANTI-TRAYS® UNDER LABORATORY CONDITIONS. HARVESTED RAINWATER IN THE COLLECTION TANK WAS POSITIVE FOR TOTAL COLIFORMS BY ALL 3 METHODS.

\begin{tabular}{|c|c|c|c|c|c|c|c|c|c|c|c|c|}
\hline & \multicolumn{3}{|c|}{ Tank 1} & \multicolumn{3}{|c|}{ Tank 2} & \multicolumn{3}{|c|}{ Tank 3} & \multicolumn{3}{|c|}{ Tank 4} \\
\hline & Body & Incubator & IDEXX & Body & Incubator & IDEXX & Body & Incubator & IDEXX & Body & Incubator & IDEXX \\
\hline $0 \mathrm{~min}$ & + & + & + & + & + & + & - & - & + & - & - & + \\
\hline $30 \mathrm{~min}$ & + & + & + & + & + & + & - & - & + & - & - & + \\
\hline $1 \mathrm{~h}$ & - & + & + & - & + & + & - & - & + & - & - & + \\
\hline $2 \mathrm{~h}$ & - & - & + & - & + & + & - & - & + & - & - & + \\
\hline $3 \mathrm{~h}$ & - & + & + & + & - & + & - & - & + & - & - & + \\
\hline $4 \mathrm{~h}$ & + & + & + & + & + & + & - & - & + & - & - & + \\
\hline $5 \mathrm{~h}$ & + & + & + & + & + & + & - & - & + & - & - & + \\
\hline $6 \mathrm{~h}$ & - & - & + & + & + & + & - & - & + & - & - & + \\
\hline
\end{tabular}

\section{Silver Fate and Environmental Implications}

In this study, the treatment efficacy was tested with "clean" and "dirty" harvested rainwater (experimental phases 1 and 2, respectively). Harvested rainwater is a generally 'clean' compared to other source waters, which may contain natural organic matter capable of binding free silver or inorganic constituents that may interfere with the colloid silver. In the presence of some anions, a low solubility precipitate on the exterior surface of the colloidal silver could form, where the precipitate shell would reduce efficacy. There are several potential precipitation reactions that could occur: $\mathrm{AgCl} \quad\left(\mathrm{K}_{\mathrm{sp}}=1.77 \mathrm{E}-10\right), \quad \mathrm{Ag}_{2} \mathrm{CO}_{3} \quad\left(\mathrm{~K}_{\mathrm{sp}}=8.13-8.46 \mathrm{E}-12\right), \quad \mathrm{AgS}$ $\left(\mathrm{K}_{\mathrm{sp}}=6.03 \mathrm{E}-37\right)$, and $\mathrm{Ag}_{2} \mathrm{SO}_{4}\left(\mathrm{~K}_{\mathrm{sp}}=1.2 \mathrm{E}-5\right) .{ }^{22}$ Phase changes at the colloid-water interface could affect the colloid reactivity and disinfecting properties.

There are additional concerns regarding impacts to aquatic health remain, since the observed concentrations exceed the $\mathrm{LC}_{50}$ values ${ }^{23}$, although the speciation of the silver, which was not determined, plays an important role in the relevance of these concentrations. For example, the D. dorotocephala $\mathrm{LC}_{50}$ is 0.03 and $>1,000$ for $\mathrm{AgNO}_{3}$ and $\mathrm{Ag}_{2} \mathrm{~S}$ respectively; similarly, the $P$. trivolis $\mathrm{LC}_{50}$ is $0.3,>1.3$, and $>1,000$ for $\mathrm{AgNO}_{3}, \mathrm{NaAgS}_{2} \mathrm{O}_{3}$, and $\mathrm{Ag}_{2} \mathrm{~S}$ respectively. While releasing silver to the environment is not desirable, silver released in the dissolved form would likely bind to colloids or particles, thus reducing its toxicity ${ }^{24}$. 


\section{Conclusions}

Preliminary findings demonstrate that colloidal silver-coated bricks may be a technically-sound POU drinking water disinfection option. There are many advantages to the substrate deployment method. When fairly high quality water was used (experiment 1), the silver treated tanks had non-detectable total coliform and E. coli effluent concentrations, which meet the W.H.O. recommended drinking water guideline and the U.S. drinking water standard, but exceeded the recommended silver guideline. When highly contaminated water was provided (Experiment 2), the initial bacterial concentrations were high and subsequently reduced to non-detectable levels after 24 hours of exposure total. A strength of this technology is that it requires no day to day maintenance, unlike chlorine or colloid silver suspensions that must be added with each use, and its efficacy is not reduced with sporadic usage, compared to biosand filters which require daily water application. Further research is needed to better understand the lifespan of a colloidal silver-coated substrate. The lifespan of the brick should be known with a high degree of certainty since there will be no indicator of the disinfecting ability being exhausted.

However, there are also disadvantages associated with the colloidal silver-coated substrate treatment. The silver concentration in these treatments exceeds human health drinking water guidelines. ${ }^{25,26}$ indicating that appropriate pairing tank size and substrate surface area are important. Reducing manufacturing inconsistencies, as well as pre-washing the bricks may alleviate some of these issues. The authors believe that human health, and therefore safe drinking water, should be the higher priority, however one should be mindful of environmental impacts, and reduce these impacts when possible. Ionic silver is known to be environmentally detrimental and dissolution of colloidal silver may contribute to ionic silver concentrations; therefore, silver release should be minimized as much as possible. Further research is needed to understand the form in which the silver is being released and the implications of use other water sources (i.e. ground- or surface water) on the treatment efficacy. Finally, at present, the cost of the colloidal silver-coated substrates is unknown, and the cost and use duration will be important parameters in determining its market appropriateness compared to other in-home treatment systems. ${ }^{19}$

\section{Limitations and Future Work}

This study explores the technical feasibility of this technology although it suffers from a number of limitations. Notably, the size and scale of community water supply systems make true replication unfeasible given the resources available for this study. Additionally, the high cost of coliform and silver testing materials make high levels of sample replication untenable. Further studies should be conducted using a variety of brick coatings to optimize the silver release within drinking water standards.

Implementation will inevitably be site-specific and need to evaluate cost concerns (which will certainly vary with the price of silver, transportation, etc.), source-water quality and composition, as well as a host of community acceptance issues. We are deeply concerned with these issues and recommend that they be considered very carefully before implementation is even considered. It should be noted that these concerns are not unique to the use of silver-based treatment technologies and need to be similarly evaluated for every project. Longer-term sustainability is beyond the scope of this project. Although it remains a concern for us, we were concerned primarily with the technical feasibility of using this technology in a certain way. As 
with other projects, long-term sustainability will need to be considered before this method is recommended on a community scale.

\section{Acknowledgements}

The authors would like to thank Brad Ponack for the production of the substrates and for applying the colloid silver coating; World Health Alliance International for supplying SilverDYNE®; Dr. Peter G. Green for assistant with ICP-MS analysis; and various member of the Engineers Without Borders student chapter at University of California Davis for their assistance with this study.

\section{References}

${ }^{1}$ De Gusseme, B., L. Sintubin, et al. (2010). "Biogenic Silver for Disinfection of Water Contaminated with Viruses." Applied and Environmental Microbiology 76(4): 1082-1087.

2 Kim, J. and B. Van der Bruggen (2010). "The use of nanoparticles in polymeric and ceramic membrane structures: Review of manufacturing procedures and performance improvement for water treatment." Environmental Pollution 158(7): 2335-2349.

${ }^{3}$ Brown, J., S. Proum, et al. (2009). "Sustained use of a household-scale water filtration device in rural Cambodia." Journal of Water and Health 7(3): 404-412.

4 van Halem, D., H. van der Laan, et al. (2009). "Assessing the sustainability of the silver-impregnated ceramic pot filter for low-cost household drinking water treatment." Physics and Chemistry of the Earth 34(1-2): 36-42.

5 Brown, J. and M. D. Sobsey (2010). "Microbiological effectiveness of locally produced ceramic filters for drinking water treatment in Cambodia." Journal of Water and Health 8(1): 1-10.

${ }^{6}$ Dankovich, T. A. and D. G. Gray (2011). "Bactericidal Paper Impregnated with Silver Nanoparticles for Point-of-Use Water Treatment." Environmental Science \& Technology 45(5): 1992-1998.

7 van Halem, D., H. van der Laan, et al. (2009). "Assessing the sustainability of the silver-impregnated ceramic pot filter for low-cost household drinking water treatment." Physics and Chemistry of the Earth 34(1-2): 36-42.

${ }^{8}$ Bielefeldt, A. R., K. Kowalski, et al. (2010). "Removal of virus to protozoan sized particles in point-ofuse ceramic water filters." Water Research 44(5): 1482-1488.

9 Silvestry-Rodriguez, N., K. R. Bright, et al. (2008). "Silver as a residual disinfectant to prevent biofilm formation in water distribution systems." Applied and Environmental Microbiology 74(5): 16391641.

${ }^{10}$ Roeder, R. S., J. Lenz, et al. (2010). "Long-term effects of disinfectants on the community composition of drinking water biofilms." International Journal of Hygiene and Environmental Health 213(3): 183-189.

12 De Gusseme, B., L. Sintubin, et al. (2010). "Inactivation of Viruses in Water by Biogenic Silver: Innovative and Environmentally Friendly Disinfection Technique." 2010 4th International Conference on Bioinformatics and Biomedical Engineering (iCBBE 2010): 5 pp.

13 De Gusseme, B., T. Hennebel, et al. (2011). "Virus disinfection in water by biogenic silver immobilized in polyvinylidene fluoride membranes." Water Research 45(4): 1856-1864.

${ }^{14}$ Rai, M., A. Yadav, et al. (2009). "Silver nanoparticles as a new generation of antimicrobials." Biotechnology Advances 27(1): 76-83.

15 Varaprasad, K., Y. M. Mohan, et al. (2010). "Hydrogel-Silver Nanoparticle Composites: A New Generation of Antimicrobials." Journal of Applied Polymer Science 115(2): 1199-1207. 
${ }^{16}$ Baumgartner, J., S. Murcott, et al. (2007). "Reconsidering 'appropriate technology': the effects of operating conditions on the bacterial removal performance of two household drinking-water filter systems." Environmental Research Letters 2(2).

17 IDEXX Laboratories: http://www.idexx.com/view/xhtml/en_us/corporate/home.jsf. Last accessed $5 / 17 / 13$

18 Brown, J., C. Stauber, et al. (2011). "Ambient-temperature incubation for the field detection of Escherichia coli in drinking water." Journal of Applied Microbiology 110(4): 915-923.

19 Ogunyoku, T. A., D. M. Nover, et al. (2011). "Point-Of-Use Drinking Water Treatment in the Developing World: Community Acceptance, Project Monitoring and Revision." International Journal for Service Learning in Engineering 6(1): 14-32.

${ }^{20}$ Ahmed, W., T. Gardner, et al. (2011). "Microbiological Quality of Roof-Harvested Rainwater and Health Risks: A Review." Journal of Environmental Quality 40(1): 13-21.

${ }^{21}$ Sazakli, E., A. Alexopoulos, and M. Leotsinidis. 2007. Rainwater harvesting, quality assessment and utilization in Kefalonia Island, Greece. Water Research 41: 2039-2047.

22 Lide, D. R. 2000. CRC Handbook of Chemistry and Physics, 2000-2001: A Ready-reference Book of Chemical and Physical Data. CRC press.

${ }^{23}$ Ratte, H. T. (1999). "Bioaccumulation and toxicity of silver compounds: a review." Environmental Toxicology and Chemistry 18(1): 89-108.

${ }^{24}$ B Nowack, HF Krug, M Height (2011) 120 years of nanosilver history: implications for policy makers. Environ. Sci. Technol. 45:1177-1183

25 E.P.A. 2011. U. S. Secondary Drinking Water Regulations: Guidance for Nuisance Chemicals.

${ }^{26}$ W.H.O. (2008). Guidelines for Drinking-water Quality. Volume 1 Recommendations. 